Estudios Constitucionales, Año 10, No 1, 2012, pp. 373 - 402.

ISSN 0718-0195

Centro de Estudios Constitucionales de Chile Universidad de Talca

"La democracia como forma de Estado: análisis de los mecanismos de participación

directa en la Constitución suiza"

Francisco Soto Barrientos

\title{
LA DEMOCRACIA COMO FORMA DE ESTADO: ANÁLISIS DE LOS MECANISMOS DE PARTICIPACIÓN DIRECTA EN LA CONSTITUCIÓN SUIZA
}

\author{
DEMOCRACY AS A FORM OF STATE: ANALYSIS OF DIRECT DEMOCRACY' \\ MECHANISMS REGULATED BY THE SWISS CONSTITUTION
}

\author{
Francisco Soto BarRIENTOS ${ }^{1}$ \\ Profesor de Derecho Constitucional, Universidad de Chile \\ fsoto@derecho.uchile.cl
}

RESUMEN: La experiencia suiza es un referente obligado a la hora de hablar de instituciones participativas y de democracia directa, no sólo por lo habitual de su uso sino por contar con una de las primeras regulaciones que incorpora en su Constitución dichos mecanismos. Esta práctica, que se remonta a la Edad Media, fue incluida en la Constitución federal de 1848 y supone incorporar la participación ciudadana en los diversos niveles de la administración, de manera crecientes desde el nivel local hasta las estructuras superiores de la administración. Esta combinación entre federalismo y mecanismos de democracia directa ha permitido en las últimas décadas, como veremos en este artículo, elaborar numerosas investigaciones sobre la conveniencia de la participación ciudadana y hacer de Suiza una particular forma de Estado. Por lo pronto, para Latinoamérica el tratamiento constitucional suizo en materia de referéndum e iniciativa legislativa popular resulta relevante, siendo antecedente directo de varias fórmulas constitucionales, como es el caso de Uruguay y Colombia.

PALABRAS CLAVE: Referéndum, participación y democracia.

ABSTRACT: The Swiss experience is a mandatory reference when talking about participatory institutions and direct democracy, not only for its common use, but becase it was one of the first regulations that incorporated these mechanisms to its constitution. This practice, dating back from medieval times, was included in the federal constitution of 1848 and implies incorporating the citizenship participation in different levels of the administration, increasingly from local level towars the superior structures of the adminsitration. This mixture between federalism and direct democracy' mechanisms has allowed over the last decades, as we will analyze in this article, to elaborate numerous researchs over the convenience of citizenship participation and making Switzwerland a particular form of State. In particular, Swiss constitutional treatment of referendum and popular legislative initiative is relevant for Latinamerica, being a direct precedent of several constitutional formulas, as in the cases of Uruguay and Colombia.

Keywords: Referendum, participation, democracy.

\footnotetext{
${ }^{1}$ Licenciado en Ciencias Jurídicas y Sociales, Magíster en Derecho Constitucional de la Universidad Diego Portales, Doctor en Derecho Universidad de Barcelona. Actualmente se desempeña como Profesor de Derecho Constitucional, de Ciencias Políticas y Académico del Programa de Doctorado de la Facultad de Derecho de la Universidad de Chile. Artículo recibido el 2 de febrero de 2012 y aceptado el 2 de mayo de 2012.
} 


\section{Forma de Estado y Forma de Gobierno}

La conformación del Estado suizo se ha transformado en una experiencia paradigmática para numerosas naciones que ven cómo las diferencias étnicas, territoriales, religiosas o culturales dividen y debilitan su convivencia. Diversas dimensiones del modelo constitucional suizo pueden ser destacadas en este sentido, como el tratamiento de los derechos fundamentales, las libertades lingüísticas o la definición de competencias en los distintos niveles de toma de decisión pública. No obstante, es el reconocimiento que Suiza da a la participación directa de la ciudadanía el sello característico de este Estado que ahora nos interesa analizar. ${ }^{2}$

\subsection{La participación como derecho fundamental.}

En primer lugar, quisiéramos constatar que existen diferencias en la regulación constitucional de la participación ciudadana y los otros derechos fundamentales. La Constitución Federal de la Confederación Suiza de 1999 (en adelante CFCS), en el capítulo primero, título segundo (artículos 7 al 36), regula el catálogo de derechos reconocidos constitucionalmente, que van desde materias generalmente contempladas en la mayoría de las Cartas Fundamentales (como los derechos de primera generación que incluyen derechos civiles y políticos) hasta las de protección de derechos sociales propios del más avanzado de los Estados europeos. En este sentido, la regulación de los derechos fundamentales -a nivel constitucional- en Suiza destacan, desde una perspectiva comparada, no sólo por el catálogo mismo de derechos garantizados sino por su nivel de resguardo. ${ }^{3}$ Además, el artículo 35 mandata a las autoridades a velar por la garantía de estos derechos, estableciendo que toda restricción deberá tener una base legal justificada por un interés público o por la protección del derecho fundamental de un tercero, y ser proporcional a su fin. Por lo demás, el Tribunal Federal, desde 1960, ha ido reconociendo una serie de otros derechos no escritos en la Constitución, como en su momento lo fueron la libertad de opinión o la propiedad. No obstante, con la Carta aprobada en el año 1999, y que entró en vigencia en el 2000, se explicitaron todos los derechos reconocidos por este tribunal. ${ }^{4}$

\footnotetext{
2 Blondel, Jean (1998): "Il modello svizzero, un futuro per I' Europa?", Revista italiana di Scienza Política, (Núm. 2), pp. 203 a 227.

${ }^{3}$ A modo de ejemplo, el tratamiento de la diversidad contempla normas específicas en la Carta Fundamental. En un tema tan relevante como el idioma, se reconocen cuatro lenguas oficiales (artículo 4 de la CFCS) y además se resguarda la libertad de idioma (artículo 184). Por tanto, se puede actuar ante los distintos niveles jurisdiccionales para garantizar este particular derecho, como ocurre con otros derechos que establece dicha Constitución.

${ }^{4}$ Thalmann, Urs (2006): "Derechos Constitucionales y Federalismos: El caso de Suiza”, en A.A.V.V. Derechos y libertades en los Estados Compuestos, (Barcelona, Editorial Atelier), pp. 101 a 120.
} 
Aunque parezca paradójico la regulación que incorpora la participación ciudadana directa no se expresa en la Constitución a través de un principio, ni tampoco como derecho, sino mediante la regulación de mecanismos participativos (referéndum y la iniciativa legislativa popular). Nos encontramos con una práctica que se prolonga en el tiempo y que ha tenido diversas maneras de regularse normativamente hasta llegar a caracterizar la forma de Estado y de gobierno suizo (explicitándose en la normativa constitucional).

El hecho de que la participación no sea regulada de manera abstracta y simplemente se le asocie a mecanismos concretos no quiere decir que no sea considerada como derecho fundamental. Thalmann explica que basta integrar el conjunto de materias descritas en el artículo 189 de la CFCS para que sean de competencia del Tribunal Federal y se le otorgue rango de derecho fundamental en Suiza. Justamente la letra C del citado artículo considera competencia de este tribunal las reclamaciones por violación de Tratados internacionales o de acuerdos intercantonales. Así el sistema constitucional suizo recoge la participación como derecho a través del reconocimiento del artículo 21 de la Declaración Universal de Derechos Humanos de 1948 y el artículo 25 del Pacto Internacional de Derechos Civiles y Políticos de 1966, donde se establece el derecho de participar en la dirección de los asuntos públicos. ${ }^{5}$

Pero la participación directa de la ciudadanía tiene una particular dimensión en el resguardo o en la restricción de derechos fundamentales. Suiza no dispone de un control jurisdiccional completo. Las leyes promulgadas por el Parlamento Federal no están sujetas a ningún tipo de control por parte de los tribunales. Esta fórmula fue establecida en la primera Constitución federal de 1848. En 1999 se efectúan modificaciones sustanciales a la Carta Fundamental, manteniendo esta excepción del control sobre leyes federales promulgadas por el Parlamento. La explicación de la falta de control judicial de las leyes se justifica en los fuertes elementos de democracia directa que tiene el proceso legislativo a nivel federal. Como señala Thalmann, prácticamente todas las leyes federales no sólo se basan en una simple mayoría del Parlamento, sino en un consenso de los partidos políticos y grupos de interés importantes en el país. ${ }^{6}$ Esta fórmula de control constitucional ciudadano hace de Suiza una democracia mayoritaria, vale decir, que la justicia no tiene la última palabra al momento de interpretar la Constitución. Nos encontramos ante una característica del Estado suizo que se diferencia de las democracias constitucionales, donde la

5 Thalmann, (2006), p. 105.

6 Thalmann, (2006), pp. 114 y 115. 
tendencia es a establecer Tribunales Constitucionales para la interpretación de la Carta Fundamental. ${ }^{7}$

La opción por esta suerte de control constitucional ciudadano nos enfrenta al dilema que se genera, cuando la voluntad de los ciudadanos limita o restringe derechos fundamentales. Este tema es de actualidad en Suiza, ya que el 29 de noviembre del 2009, mediante referéndum, la ciudadanía aprobó una propuesta de reforma constitucional para limitar la libertad religiosa establecida en el artículo 72 de la Constitución, prohibiendo la construcción de "minaretes" en las mezquitas que se construyan en el futuro en Suiza.

En este sentido, el año 2003 se aprobó una importante reforma constitucional que introdujo el numeral 2 al artículo 139 de la Carta Fundamental suiza, relativo a las iniciativas de referéndum cuyo objetivo sea reformar de manera parcial a la Carta Fundamental. Aquél señala que cuando una iniciativa popular no respete el principio de "unidad de la forma", el de "unidad de la materia" o las disposiciones imperativas de derecho internacional, la Asamblea Federal deberá declararla total o parcialmente nula. Por tanto, el sistema representativo cuenta con una importante herramienta de resguardo frente a situaciones extremas. Estamos ante una forma de control político entregada discrecionalmente a los representantes y que permite velar por la constitucionalidad de iniciativas que son aprobadas mediante consulta ciudadana. En consecuencia, a partir de esta reforma del 2003 y bajo los supuestos mencionados, la voluntad popular expresada mediante referéndum puede ser considerada inválida por la Asamblea Federal.

\subsection{La participación y el modelo de descentralización suizo}

Con todo, esta fórmula suiza de reforma constitucional contiene un potencial contradictorio entre el desarrollo de la democracia y derechos fundamentales, con las limitantes antes señaladas. Esto se debe complementar, además, con el

\footnotetext{
7 Las constituciones suelen elaborarse por "convenciones" constituyentes, elegidas por el pueblo con el único propósito de elaborarlas y éstas suponen un procedimiento distinto al ordinario de elaboración de leyes. Incluso parece que las primeras experiencias de judicial review of legislation tuvieron lugar de la mano de instancias jurisdiccionales de los Estados, con el fin de poner límites jurídicos al poder de la legislatura. Con estas características se elabora la Constitución federal de 1787. No obstante, el modelo constitucional de EUA puede ser visto como una alternativa algo distinta en este sentido, ya que concilia la tendencia democrática del constitucionalismo estatal, expresada en la Carta Fundamental nacional, con las cartas fundamentales de los Estados federales, donde buena parte de ellas es aprobada mediante referéndum. Esto último no obsta al control de constitucionalidad, tanto por los tribunales estatales como por los federales. Tarr, Allan (1998): Understanding State Constitutions, (Princeton, Princeton University Press), pp. 26 y 27 y García Pelayo, Manuel (1984): Derecho Constitucional Comparado, (Madrid, Editorial Alianza), pp. 333 y sig.
} 
tramado participativo que opera en los diversos niveles de descentralización del Estado, ya que en términos generales los potenciales elementos disruptivos que generen las fórmulas participativas pueden ser relativizados a través de los propios procedimientos que la regulan. Así la puesta en práctica de los mecanismos de democracia directa y participativa en Suiza debe complementarse con los controles y procedimientos desarrollados a través de la particular estructura de este Estado federal. Ello ha sido caracterizado como el "federalismo desde la base", ya que supone crecientes grados de participación desde el nivel local hasta las estructuras superiores del orden federal. Por tanto, al estudiar la forma cómo el Estado suizo se expresa territorialmente, junto con atender a las competencias del nivel federal, cantonal o comunal, se debe analizar el rol que desempeña la ciudadanía en cada uno de estos niveles. La participación ciudadana, vista como una contribución a la descentralización en la toma de decisiones y al resguardo y actualización de los derechos fundamentes, ha caracterizado la forma de gobernar en Suiza y ha permitido una evolución a la actual forma de Estado y de Gobierno. Este proceso supone importantes niveles de particularidad en el sistema institucional en cada cantón y comuna.

Sin embargo, paralelo al fenómeno de la participación se encuentra el de la negociación. Esta tendencia a buscar un diseño institucional capaz de integrar en una fórmula colegiada a los diversos sectores políticos se consolida con la Constitución de 1999 y tiene directa incidencia en la utilización de mecanismos de democracia directa. Dichos mecanismos operan, en definitiva, cuando el modelo institucional de acuerdos fracasa o no es capaz de incorporar las opiniones alternativas que motivan la realización de una consulta ciudadana. ${ }^{9}$

Así, este modelo intencionadamente busca, dentro de sus objetivos institucionales, acotar la divergencia en los temas de interés público. Esto supone, por una parte, anticipar posibles conflictos que surgen del amplio reconocimiento de estas fórmulas participativas y por la otra, buscar apoyos en los más diversos referentes ciudadanos. De esta manera la sola expectativa de utilización de mecanismos de democracia directa ha generado en los órganos representativos al menos tres consecuencias: el modelo uni-partidario de gobierno se transforma progresivamente en uno pluri-partidario; se produce un sistema de negociación con los diferentes grupos de interés previo a la implementación de una inicia-

\footnotetext{
${ }^{8}$ SÁNCHEZ Ferriz, Remedio (2001): Suiza sistema político y constitucional, (Madrid, CEC), pp. 43 y De VerGOTTINI, Giuseppe (1985): Derecho Constitucional Comparado, (Madrid, Espasa-Calpe), pp. 486 y sig.

9 KRIESI, Hanspeter (2008): Direct democratic choice, the Swiss Experience, (Lanham Lexington Books), pp. 22 y sig.
} 
tiva, ya sea legislativa o administrativa; y, además, se efectúan negociaciones posteriores a las medidas de la autoridad, cuando así lo requieren iniciativas ciudadanas de carácter propositivo. ${ }^{10}$

Un buen ejemplo de esta institucionalización de la negociación es la particular característica de la forma de gobierno en Suiza. Los órganos de la federación han asumido un diseño original; no existe un Jefe de Estado, ya que el Poder Ejecutivo reside en una instancia colegiada que lleva el nombre de Consejo Federal. Todos sus miembros tienen la misma jerarquía, no obstante uno hace las veces de presidente como representante formal. Una ley sobre la organización del Gobierno y la administración de 1997 regula su funcionamiento, y sus competencias se encuentran establecidas en el artículo 180 de la CFCS. La elección de cada consejero se realiza de manera individual y se requiere mayoría absoluta de la Asamblea Federal. Una vez elegidos los consejeros, dicho órgano no puede removerlos y permanecen en sus cargos durante un período de cuatros años con posibilidad de reelección. ${ }^{11}$ Este carácter colegiado imprime por sí sola la necesidad de acuerdo dentro de un espectro político bastante amplio, que se expresa también en la Asamblea Federal, instancia que ejerce la función legislativa. ${ }^{12}$

En este ámbito se hace presente un particular mecanismo de democracia participativa: la conformación de comisiones asesoras para las definiciones legislativas. Éstas son instancias extraparlamentarias creadas por la administración

${ }^{10}$ Papadopoulos, Yannis (1997): Les processus de decisión fédéraux en Suisse, (Paris, L’Harmattan), p. 38.

${ }^{11}$ Loewenestein, $\operatorname{Karl}$ (1979).: Teoría de la Constitución, (Barcelona, Ariel), p. 144.

12 La Asamblea Federal se constituye por dos Cámaras: el Consejo Nacional, cuya elección es directa por la ciudadanía; y el Consejo de los Estados, elegidos por los cantones. Esta estructura bicameral, que hoy es propia de la mayoría de los Estados compuestos, supuso desplazar el modelo original que descansaba en la Dieta. Recién es con la Constitución de 1789, y posteriormente con la Carta de 1848, cuando se asume la idea de dos Cámaras. La Asamblea Federal se reúne cuatro veces al año y sus funciones están reguladas en el artículo 157 de la CFCS. Lo habitual entonces es que sesionen ambos Consejos por separado, reservando para actividades de suma relevancia la reunión de la Asamblea, como el nombramiento del canciller, de los consejeros federales, de los jueces del Tribunal Federal o para resolver conflictos de competencia entre autoridades federales, entre otras materias. Existe un reparto de atribuciones y facultades entre las Cámaras, que tienen de los mismos derechos y obligaciones. El Consejo Nacional se encuentra integrado por 200 parlamentarios, elegidos de forma directa por la población, mediante un sistema proporcional establecido en una ley de 1919. No obstante, en cinco cantones y semi-cantones que eligen un sólo representante, se aplica en consecuencia un sistema mayoritario. El número de parlamentarios establecidos para cada cantón es actualizado cada 10 años. Puede participar en las elecciones de esta cámara todo ciudadano suizo mayor de 18 años y que cumpla con lo establecido en el artículo 136 de la Constitución. El Consejo de los Estados se compone de 46 diputados de los cantones. Cada cantón nombra 2 diputados, excepto 6 que nombra sólo uno. La modalidad de elección de los diputados es establecida por cada cantón, predominando la elección directa de la ciudadanía. ARgUllol MurgaDAs, Enric (2004): Federalismo y autonomía, Barcelona, Editorial Ariel), pp. 160 y sig. 
para consensuar eventuales iniciativas legislativas. Desde la década de los setenta el número de comisiones ha llegado a 370, de las cual el $70 \%$ ha sido de carácter permanente y con un número de integrantes que supera los 5.000 representantes (de distintos grupos de interés). Dichas comisiones coordinan debates permanentes entre los más diversos sectores políticos, en materias muchas veces específicas y técnicas, pero también en otras de carácter general, como la modernización del Estado o la transparencia. ${ }^{13}$

Con todo, la principal instancia de negociación opera en la particular dinámica federativa. El rol fundamental y originario de la Federación está definido en el artículo 2 de la CFCS; dentro de sus fines contempla proteger la libertad y derechos del pueblo, asegurar la independencia y seguridad del país y favorecer la prosperidad común, el desarrollo y la cohesión interna. De este modo, la Carta Fundamental entrega una serie de competencias al Gobierno central en materia legislativa, jurisdiccional y administrativa; el principio general establecido en el artículo 3 de la CFCS es el de la competencia cantonal: "Los cantones son soberanos, en la medida en que en su soberanía no se encuentre limitada por la Constitución Federal, y ejercen todos los derechos que no estén delegados a la Confederación".

Esta regla general supone en la práctica un grado de flexibilidad que distingue este modelo del de los EUA. Según García-Pelayo, el modelo suizo es mucho más "elástico" que el americano, ya que la ejecución de las leyes federales se lleva a cabo a través de los cantones y supone además consultas frente a la elaboración de normativas a aplicarse en su territorio. Esto permite contar con una autoridad cercana y única como contraparte para que el control ciudadano sea realmente efectivo. ${ }^{14}$

No obstante, una primera dimensión del federalismo suizo, más allá de los matices señalados, descansa en la afirmación de la autoridad cantonal frente al poder central. Los cantones son colectividades públicas descentralizadas y soberanas, según lo dispone el artículo 3 de la CFCS, no reconociendo más límite que los establecidos por ésta. El sistema suizo supone resguardar tanto la soberanía nacional como cantonal. El artículo 53 de la CFCS señala que para ser modificada la existencia o estatuto de cada cantón debe ser sujeto a una mediación constitucional (este artículo establecido en la reforma constitucional de 1999); se requiere una mayoría del pueblo suizo y también del cantón, sometiéndose luego a la aceptación de la Asamblea Federal bajo la forma de una resolución federal.

13 Ulieri, Pier Vincenzo (2003): Referendum e Democrazia, una prospecttiva comparata, (Bologna, Il Mulino), pp. 209 y 210.

${ }^{14}$ García Pelayo (1984), pp. 534 y 535. 
Los cantones por ley regulan la política exterior y colaboran en la preparación de las decisiones que afectan a sus intereses esenciales, sin menoscabar la actuación de la Confederación ("principio de mutua ayuda", artículo 44 de la CFCS). De esta manera, ejercen su labor legislativa en los diversos ámbitos de su competencia, regulando directamente importantes materias como la educación, salud, seguridad pública, comercio, ordenamiento territorial y organización judicial. Con todo, existen materias que quedan fuera de las facultades cantonales como la regulación civil y penal. ${ }^{15}$ Es importante destacar la tradición de cooperación entre los cantones y la autoridad central. Se habla de un "federalismo cooperativo", donde en diversas instancias se establecen fórmulas de coordinación, desde las reuniones entre Ministros hasta los grupos de contactos. Es importante destacar que, coherente con el mismo principio que opera a nivel federal, el artículo 50 de la CFCS reconoce que la autonomía de la comuna está dada por los límites de los derechos de los cantones. Existen actualmente 2.903 municipios; cada uno de ellos contempla mecanismos particulares de participación directa. Muchas de estas fórmulas tienen origen anterior a los institutos establecidos en la Carta Fundamental suiza. Con todo, la fórmula institucional más recurrente a nivel local son las consultas obligatorias. A modo de referencia, en el período 1970-1999 se registraron 3.339 consultas locales de este tipo. ${ }^{16}$

La actual composición del Consejo Federal, de las Comisiones Asesoras, de la Asamblea Federal; la institucionalidad Cantonal, y la local suponen sus medidas adoptadas concitando un alto grado de consenso. Incluso, en propuestas elaboradas por la propia ciudadanía -como la iniciativa legislativa popular- la búsqueda de consensos políticos se hace necesaria. Tauxe destaca el grado de acuerdo que debe existir en este tipo de iniciativas para que sean votadas favorablemente por la Asamblea Federal. Aunque dichas propuestas cuentan ya con un grado importante de apoyo ciudadano (al ser sometidas a este proceso participativo con un resultado favorable), en la fase legislativa se introducen enmiendas y correcciones muchas veces sustanciales. Por tanto, el factor de negociación política no sólo

\footnotetext{
${ }^{15}$ El debate legislativo se realiza a través del gran Consejo Cantonal, que es por regla general monocameral. Existen diferencias entre uno y otro pero normalmente los consejeros duran cuatro años. La disolución de la asamblea puede pedirse contando con un cierto número de electores. En las elecciones se utiliza un sistema mayoritario. Dicho consejo vota las leyes que son propuestas por el Consejo de Estado, establece los impuestos y fija el presupuesto. Además, nombra a los jueces, basado en una cierta autonomía cantonal que se remonta a la lucha contra los Habsburgos. Las causas civiles relevantes son de competencia del tribunal del distrito y, si lo son más, del tribunal cantonal. El Gobierno se ejerce por colegios o consejos compuestos por siete miembros. El Parlamento o el Pueblo pueden revocarlos. SÁnchez Ferriz (2001), pp. 75 a 77.

${ }^{16}$ SÁnchez Ferriz (2001), pp. 80 y 81.
} 
opera previamente a la participación directa de la ciudadanía, sino también con posterioridad. ${ }^{17}$

Los mecanismos de democracia directa se convierten en la última alternativa de los sectores que no han logrado incorporar sus demandas en una iniciativa de reforma constitucional o legal. Esto se hace evidente al analizar las diversas fórmulas participativas que contempla la CFCS. El énfasis del modelo suizo en la participación y la negociación se potencia y da el sello institucional que actualmente caracteriza a ese país. A continuación nos detendremos a analizar en detalle las fórmulas de consulta federal y su implementación en los últimos años.

La combinación entre federalismo y mecanismos de democracia directa convierte a Suiza en un "laboratorio democrático", permitiendo la comparación de las diversas fórmulas participativas entre los cantones y las comunas que lo integran, dimensionando la importancia que tienen en los procesos participativos los partidos políticos, los promotores de las iniciativas y el Gobierno, entre otros actores relevantes, en la implementación de fórmulas participativas. Así, sistemas institucionales de todo el mundo, en particular los latinoamericanos, han recogido la experiencia suiza en sus cartas fundamentales; pero además las numerosas investigaciones de campo permiten despejar una serie de prejuicios sobre la participación ciudadana directa y su relación con diversos aspectos de las democracias representativas. ${ }^{18}$

De este modo, se ha podido identificar, por ejemplo, que existe una directa relación entre la participación local y el compromiso de los ciudadanos en procesos participativos cantonales y federales; que la experiencia de los votantes en estos procesos de democracia directa promueve la eficacia política y estimula el debate público ${ }^{19}$; que se dan efectos positivos de estos procesos en los gobiernos, fortaleciendo la capacidad de recepción de las demandas ciudadanas ${ }^{20}$; y que se produce un efecto integrador y legitimizador de los mecanismos de democracia directa en la ciudadanía (incluso generaría importantes niveles de satisfacción en las personas que participan de estas consultas). ${ }^{21}$

\footnotetext{
${ }^{17}$ TAUXE, Lionel (2007): "La concrétisation législative des initiatives populaires fédérales acceptées en votation: un processus aux outputs très incertains”, Swiss Political Review, (Núm. 13), pp. 433 a 458.

18 Auer, Andreas, Malinverni, Giorgio, Hottelier, Michel (2000): Droit constitutionnel suisse, (Bern, Staempfli) tomo I, pp. 50 y sig.

19 KrIESI, Hanspeter (1995): Le sytème politique suisse, (París, Economica), p. 12.

20 Lupia Arthur y Matsusaka John G. (2004): "Direct Democracy: New Approaches to Old Questions", Annual Review of Political Science, (Núm.7), pp. 463 a 482.

${ }^{21}$ Frey, Bruno y StUtZer, Alois (2002): Happiness and Economics, (Princeton and Oxford, Princeton University Press), pp. 200 a 220.
} 
Estudios comparativos a nivel cantonal y local efectuados desde la perspectiva económica documentan también las consecuencias positivas de estas instituciones de democracia directa: mejor desempeño macroeconómico, reducción de deuda pública, reducción de gastos generales (e incluso gastos médicos en particular), reducción de niveles de evasión de impuestos y mejoras en servicios públicos. $^{22}$

Cuando una forma de Gobierno participativa se consolida de esta manera, asume un carácter de tendencia permanente y acaba por influir en la misma concepción del Estado. Desde la perspectiva comparada esto sólo puede decirse de la relación que el Estado suizo ha generado con los mecanismos de democracia directa y participativa. En las restantes experiencias que analizaremos, con dificultad encontraremos experiencias participativas que asuman un protagonismo importante aunque no llegan a incidir de manera habitual en la forma de Estado y de Gobierno. ${ }^{23}$

Lijphart, que clasifica y analiza 36 Estados democráticos según sus atributos, llega a la conclusión que Suiza constituye el caso más paradigmático de democracia consensual en la tipología de regímenes democráticos occidentales. Las instituciones políticas suizas caracterizadas por gabinetes de amplias coaliciones, equilibrio en las atribuciones con que cuentan Ejecutivo y Legislativo, sistemas multipartidistas, representación proporcional, fuertes resguardos y facultades para los grupos de interés, federalismo y gobierno descentralizado, independencia del Banco Central y sistema bicameral contribuyen a un poder político compartido. Es importante notar que este autor llega a tal caracterización del modelo institucional suizo sin incluir los mecanismos de democracia directa. ${ }^{24}$

Así el análisis de Lijphart nos permite constatar anticipadamente que no sólo mecanismos como el referéndum y la iniciativa legislativa popular en Suiza buscan contribuir a establecer un alto grado de acuerdo en las decisiones políticas; es todo el modelo institucional el que se estructura en este sentido. Por eso, aunque nuestro objetivo es la revisión de la normativa constitucional establecida en la Carta de 1999, conviene hacer un rápido repaso de la evolución de las fórmulas participativas y del Estado suizo en sus diversos niveles.

22 Feld, Lars y Kirchgässner, Gebhard (2001): "The political economy of direct legislation: Direct democracy and local decision-making", Economic Policy, (Núm. 16), pp. 329 a 367, y "Does direct democracy reduce public debt evidence from Swiss municipalities", Public Choice, (Núm. 109), pp. 347 a 370.

23 De Vergottini (1985), p. 117.

${ }^{24}$ Lijphart, Arend (1999): Patterns of democracy, (New Haven, Yale University Press), pp. 34 a la 41. 


\section{LA EVOLUCIÓN DE LOS MECANISMOS DE DEMOCRACIA}

\section{DIRECTA Y PARTICIPATIVA}

La conformación de lo que suele llamarse la "Confederación Antigua", que se extiende desde fines del siglo XIII hasta la época de la Revolución Francesa, es uno de los primeros antecedentes del constitucionalismo europeo. En este período los cantones comienzan a establecer un equilibrio entre unidad y grados crecientes de autonomía. Es importante precisar que en esta etapa no se logró establecer un Estado, ya que todavía no existía gobierno ni justicia centralizada, y sólo algunos cantones contaban con una verdadera autonomía. Pero es en este período cuando se comienza a perfilar el modelo institucional que caracterizará a Suiza hasta hoy.

La relación entre cantones se establecía a través de acuerdos bilaterales diversos en contenido. A pesar de todo, existía una alianza entre los cantones definida por su perdurabilidad y efecto frente a los otros Estados, ante los cuales eran vistos (el conjunto de cantones) como una unidad. Es justamente a partir de este proceso de integración entre distintas comarcas que surge la Dieta como instancia de reunión anual y de toma de acuerdos que se adoptan por unanimidad. Con todo, ya se evidencia el protagonismo de los mecanismos de democracia directa como fórmula de control de las autoridades políticas. Los representantes debían limitarse a cumplir un mandato imperativo y, si surgía algún asunto que excedía sus facultades, actuaban ad audientum para pasar ad referendum. ${ }^{25}$

No obstante, a pesar de las particularidades cantonales, desde 1830 el modelo institucional suizo supone un predominio de la participación directa de la ciudadanía por sobre el tradicional sistema representativo. Según Ulieri, este momento puede ser entendido a partir de tres características: las principales definiciones públicas son adoptadas cantonalmente a través de Asambleas públicas; una Asamblea Constituyente es la encargada de elaborar la Constitución Federal; y dicha Carta Fundamental debía ser ratificada a través de una consulta popular. ${ }^{26}$

Podemos contar, quizá como una de las pocas experiencias europeas, la particular compatibilidad que Suiza logra entre la participación directa de la ciudadanía generada a través de Asamblea pública, mecanismo característico de la práctica municipal medieval y que tiene por objeto expresar la voluntad de la comunidad, con fórmulas como la Asamblea Constituyente que surge de la mano de las doctrinas sobre la soberanía. ${ }^{27}$

${ }^{25}$ KRIESI (1995), p. 82.

${ }^{26}$ ULIERI (2003), p. 135.

27 Fioravanti, Maurizio (2007): Constitución, de la antigüedad a nuestros días, (Madrid, Editorial Trotta), p. 54. 
Ésta fue la inspiración política que contextualizó la Carta Fundamental de 1848 y que conformó en definitiva a la Confederación Helvética. Desde este momento los mecanismos de democracia directa ocupan un papel central en el modelo institucional suizo, ya que no existía confianza en la actuación de los representantes en las definiciones si éstas no eran refrendadas por los ciudadanos del propio cantón. Es justamente en el rol fundamental de la participación directa de la ciudadanía que concuerdan los distintos sectores políticos, que van desde los federalistas católicos y protestantes hasta los sectores más progresistas y laicos, partidarios de un modelo institucional más centralizado. ${ }^{28}$

Se establecieron dos mecanismos de democracia directa: el referéndum obligatorio frente a iniciativas de reformas que modifiquen parcial o totalmente la propia Constitución; y la iniciativa ciudadana de ley, para la reforma de la Constitución, en todo o parte. En este segundo caso se debía contar con el patrocinio de 50.000 ciudadanos con derecho a voto presentes en, a lo menos, ocho cantones. El referéndum a nivel federal fue establecido en $1848^{29}$, siendo facultativo en materia legal desde 1874. En 1921 se amplió a algunos Tratados internacionales, para que en 1977 se extendiera a todo tipo de documentos internacionales. Las temáticas susceptibles de ser consideradas para referéndum obligatorio han ido extendiéndose sistemáticamente, separándose de las iniciativas referidas a la reforma constitucional. Así se llega a la fórmula, aprobada en 1999 y modificada el 2003, que supone tres tipos de referéndum: reforma constitucional (total o parcial), obligatorio y facultativo.

En lo concerniente a los mecanismos de democracia directa establecidos en el nivel cantonal, la Constitución de 1848 desencadenó un masivo proceso de regulación en las Cartas Fundamentales, que va desde normativas que establecen posibilidades de veto ciudadano a cualquier proyecto de ley hasta el referéndum obligatorio frente a materias específicamente descritas, pasando por el referéndum facultativo (en manos de los respectivos Gobiernos cantorales). A su vez, en este período tienen origen las consultas ciudadanas para refrendar materias de finanzas públicas. En algunos cantones los primeros antecedentes de este tipo de referéndum se remontan a las primeras cartas fundamentales como la de Basilea-Campagna (1849), San Gallo (1862) y Lucerna (1864); pero es en el cantón de Vallese donde cobra notoriedad este tipo consultas, ya que se

\footnotetext{
${ }^{28}$ ULIERI (2003), p. 137.

29 La Constitución de 1848 fue aprobada con el apoyo de 145.584 ciudadanos; y 54.320 se manifestaron en contra. En consecuencia, el apoyo inicial de este modelo institucional no fue unánime, ya que un tercio de la población mantuvo un explícito rechazo a dicha carta.
} 
establece como obligatoria (1839). Hoy el referéndum financiero es obligatorio en ocho cantones. ${ }^{30}$

La regulación de estos mecanismos de democracia directa es otra diferencia que se puede constatar a nivel cantonal; varía en el número de firmas requeridas, las condiciones de validez y el plazo para que la iniciativa deba interponerse (en el caso de iniciativa legislativa popular). A partir de estas diferencias una ley de diciembre de 1976 regula las múltiples manifestaciones del ejercicio de los mecanismos de democracia directa, estableciendo estándares mínimos comunes para los diferentes cantones. ${ }^{31}$

En cuanto a la revocación de mandato, esta figura se encuentra prevista para cargos de elección popular de nivel cantonal. En algunos cantones se utiliza para remover de sus cargos a parlamentarios, así como para los integrantes de Comités Ejecutivos. ${ }^{32}$

A nivel local, los mecanismos cantonales se replican como los referendos obligatorios y facultativos. Un particular mecanismo del ámbito local es la landsgemeinde, que hace referencia a la reunión de la totalidad del cuerpo electoral, generalmente en una plaza de la ciudad, una vez al año. También puede reunirse de manera extraordinaria a requerimiento del Consejo Cantonal o a solicitud de un número determinado de ciudadanos. La votación es a mano alzada. Las atribuciones de esta instancia tienen que ver con el ámbito legislativo: la revisión de la Constitución; la aprobación de proyectos de ley y del presupuesto; la concesión de ciudadanía; la aprobación de decretos que signifiquen gastos; y la supresión o creación de empleos, entre otras materias. También tiene atribuciones electorales, ya que a través de esta instancia se elige el Consejo Consultivo del cantón, además de los miembros de los tribunales principales y los funcionarios superiores de la administración local y cantonal. ${ }^{33}$

Así, a través de esta breve reseña de la evolución del sistema participativo suizo podemos constatar cómo existe una interconexión entre los procesos locales y cantonales y su reconocimiento en la Carta de 1848 y sus posteriores modificaciones. Si bien no se puede decir que las experiencias participativas locales y cantonales fueron las que fundamentaron la consagración constitucional de las diversas formas de referéndum, sin duda conformaron un antecedente importante.

30 Ulieri (2003), p. 139.

${ }^{31}$ SÁnChez Ferriz (2001), p. 84.

32 Sánchez Ferriz (2001), p. 56.

33 SÁnChez FERriz (2001), p. 84. 


\section{MeCANISMOS DE DEMOCRACIA DIRECTA EN LA}

CARTA DE 1999

\subsection{Disposiciones generales}

El referéndum es una herramienta establecida por la Constitución para que el pueblo y los cantones se pronuncien como última instancia sobre la adopción o rechazo de un texto legislativo o constitucional, según lo establece el título IV de la CFCS, denominado "Pueblo y Cantones". En este sentido, es importante reiterar la evidente conexión que el legislador quiere explicitar entre los mecanismos de democracia directa y el resguardo de la autonomía expresada a través de los cantones, idea que por lo demás surge del origen de dichas instituciones en el sistema institucional suizo, como ya hemos advertido. ${ }^{34}$

El primer capítulo del mencionado título lleva la rúbrica de "disposiciones generales", y contiene dos artículos: uno referido a los derechos políticos del pueblo y otro que regula el papel de los partidos políticos (artículo 136 de la CFCS). Esta referencia supone una aplicación común a los tres tipos de referéndum regulados en este título. En dicho artículo se señala además que todos los ciudadanos mayores de 18 que no estén impedidos por causa de "enfermedad o retraso mental" tienen derechos políticos en el plano federal, contando con los mismos deberes y derechos que dicha carta dispone para el ámbito nacional. Hasta aquí se podría pensar que esta norma busca definir los sujetos activos de los mecanismos de democracia directa únicamente, no obstante, en el inciso segundo señala que los referidos ciudadanos podrán formar parte en la elección del Consejo Nacional y en las otras votaciones federales, así como proponer y firmar iniciativas populares y referendos en materia federal. De esta forma hace extensiva dicha norma a todos los mecanismos de participación política, con excepción de las definiciones que se adopten en este sentido en el plano local.

Por su parte, el artículo 137 reconoce explícitamente el rol de los partidos como instancias preferentes para la formación de la opinión pública y la voluntad popular. Pese al central protagonismo que el sistema suizo otorga a los mecanismos de democracia directa, tales instrumentos no pretenden disminuir el rol protagónico de los partidos políticos, ni se presentan en contradicción con ellos. La referencia explícita a los partidos políticos en las disposiciones generales supone un mandato al legislador y a la autoridad administrativa de hacer operativo este rol en los diferentes procesos de consulta.

${ }^{34}$ De Vergottini (1985), p. 485. 


\subsection{Referéndum de reforma constitucional}

La CFCS, en sus artículos 138, 139, 139a y 139b regula particularmente dos modalidades de iniciativas populares para reformar la Constitución: total o parcial. El artículo 139 contemplaba, desde el 2003, la posibilidad también de iniciativas populares genéricas, pero a poco andar esta modalidad fue derogada de la Carta suiza (producto de una iniciativa parlamentaria, que luego de su trámite legislativo se sometió a referéndum obligatorio el 27 de septiembre del 2009). ${ }^{35}$

Como ya hemos señalado, el sistema institucional suizo entrega cierto nivel de participación a la ciudadanía en el resguardo constitucional. El artículo 189a de la CFCS establece la competencia del Tribunal Federal para resolver eventuales violaciones de derechos constitucionales. Por ello cobran protagonismo las competencias que, a través de los mecanismos de democracia directa, la Constitución entrega a la ciudadanía en el ámbito federal; por ejemplo, las reformas a la Carta Fundamental, así como la definición de materias vinculadas a la concreción de derechos fundamentales, deben ser sometidas a referéndum. Se puede hablar, en consecuencia, de un modelo de resguardo de constitucionalidad que involucra a la ciudadanía. A fin de cuentas, son los ciudadanos suizos también los responsables de la continuidad en el ordenamiento jurídico constitucional.

Tanto para la reforma total como la parcial se exige la firma de 100.000 ciudadanos con derecho a voto. De igual forma, el plazo para acreditar estas firmas es de 18 meses, que corren desde la publicación en el diario oficial de la solicitud de la adopción, modificación o abrogación de disposiciones constitucionales. Para la reforma parcial de la Carta Fundamental se requiere además que el proyecto sea presentado por escrito. ${ }^{36}$

Otra diferencia que tiene entre sí la reforma total y parcial es a quién se consulta. En la reforma total participa en el referéndum la totalidad de electores suizos; mientras que en la parcial junto al pueblo y participan los cantones (contándose a partir de la votación mayoritaria que se alcance en dicha división territorial). Esta

\footnotetext{
35 La modalidad de reforma genérica de la Carta Fundamental nunca se había utilizado, ya que suponía la promulgación de una ley que no había sido aprobada por el Parlamento, pese a que desde mayo del 2006 se estaba discutiendo un proyecto en este sentido en el Consejo Federal. Pero además, esta modalidad de iniciativa popular resultaba muy difícil de implementar dentro del modelo institucional suizo, que analizaremos a continuación. La capacidad de presentar una contrapropuesta que tiene el Parlamento, las diferentes mayorías requeridas para la aprobación de las enmiendas constitucionales, la posibilidad de solicitar al Tribunal Federal para verificar la aplicación correcta por parte de una iniciativa genérica aprobada, hacían ineficiente esta institución.

36 Jaria Manzano, Jordi (2001): "El federalismo suizo, una respuesta a una sociedad plural", Revista Vasca de Administración Pública, (Núm. 61), pp. 89 a 136.
} 
distinción se aplica de igual manera a los contraproyectos que presente la Asamblea Federal, según sea el caso de iniciativa que contradiga (reforma total o parcial).

El artículo 142 señala una norma general para todos los tipos de referendos regulados por la CFCS relativa a cómo se obtiene la aprobación de una consulta. Primero, y como es imaginable, los actos sometidos a la votación popular se aceptarán por mayoría de los votantes. Esto se dificulta cuando una iniciativa debe ser consultada al pueblo y a los cantones. Aquí el citado artículo señala que los actos sometidos a la votación popular y a la de los cantones necesitarán ser aprobados por la mayoría de los votantes y también de los cantones para que se acepten. El resultado del voto popular en un cantón representa la voluntad de éste. En consecuencia, la diferencia entre una u otra modalidad resulta importante, ya que, tratándose de modificaciones constitucionales que hayan sido aprobadas, si uno de los proyectos obtiene la mayoría de votos de los electores y el otro la mayoría de los cantones, el proyecto que entre en vigor será el que haya obtenido el porcentaje más elevado de votos de la población y de cantones (artículo 139b). Cabe recordar que desde 1891 -fecha en que se estableció la iniciativa popular para la revisión constitucional parcial-sobre un total de casi de 160 iniciativas que fueron objeto de consulta sólo quince fueron finalmente aceptadas por el electorado y los cantones. ${ }^{37}$ Las exigencias en el modelo suizo de referéndum constitucional se concentran, en consecuencia, en el número de firmas requeridas para la consulta, sin establecer mayores formalidades de contenido o forma.

Dos importantes límites a las modificaciones constitucionales por vía de referéndum se establecieron en el año 2003. El primero se refiere la facultad de la Asamblea Federal para declarar total o parcialmente nula una iniciativa de reforma constitucional cuando no respete el principio de "unidad de la forma", el de "unidad de la materia" o las disposiciones imperativas de derecho internacional (artículo 139.2 de la CFCS) como ya se ha visto. Las restricciones referidas a la unidad de forma y de fondo buscan mantener la coherencia de la Constitución. En consecuencia, a pesar de que una reforma constitucional cumpla con todas las etapas del proceso constitucional no entrará en vigencia, aunque sean aprobadas directamente por la ciudadanía, si éstas son heterogéneas, carentes de sentido unitario, y que no puedan reducirse a una cierta lógica material o formal. Mientras, la otra alternativa supone un ejercicio más específico a la Asamblea Federal que supone comparar las reformas parciales a la Constitución con el catálogo de disposiciones imperativas del derecho internacional aprobado por Suiza y que se encuentre vigente.

37 TAuxe (2007), p. 436. 
En la mayoría de las experiencias comparadas este tipo de restricciones opera antes que la iniciativa popular sea consultada, en el período de admisibilidad. Así se evita comprometer expectativas y recursos en propuestas que no cuentan con una mínima posibilidad de concreción. Por otra parte, las experiencias comparadas remiten este tipo de decisión a una instancia jurisdiccional donde se desarrolle un razonamiento jurídico y se pueda elaborar jurisprudencia en este sentido. Por lo pronto, las restantes experiencias que analizaremos en Europa (Italia y España) y Latinoamérica optan por establecer un control jurídico y no político en esta etapa.

Este pronunciamiento de la Asamblea Federal hasta la fecha no registra antecedentes; probablemente, el primer caso será la iniciativa aprobada por referéndum relativa a la prohibición de construcción de "minaretes" en las mezquitas, por su evidente restricción a la libertad de culto consagrada, en el artículo 9 del Convenio Europeo para la Protección de los Derechos Humanos y de las Libertades Fundamentales (de noviembre de 1950).

La otra modificación incorporada el año 2003 se refiere a la facultad de la Asamblea Federal de aceptar o rechazar una iniciativa popular antes de ser sometida a referéndum y de presentar un contraproyecto para ser consultado en conjunto. En esta hipótesis la definición de la Asamblea Federal no tiene limitantes, y a diferencia del caso anterior -que supone el cumplimiento de ciertas condiciones, como el principio de unidad de la forma, el de unidad de la materia o las disposiciones imperativas de derecho internacional- este pronunciamiento es puramente político. Dicho de otra manera, es facultad de la Asamblea Federal decidir si rechaza o aprueba una iniciativa de reforma parcial de la Constitución.

En consecuencia, la Asamblea Federal puede aprobar la iniciativa para la consulta parcial (artículo 139.3 de la CFCS) y el referéndum se efectúa sin mayores variaciones. Si rechaza la iniciativa sin proponer un contraproyecto y aquélla es finalmente aprobada por referéndum, la Asamblea Federal elaborará las correspondientes modificaciones constitucionales, salvo que concurran las circunstancias descritas en artículo 139.2 y 3 de la CFCS, en cuyo caso deberá declarar nula toda la propuesta o parte de ella.

Se establece además un procedimiento común, en el artículo 139 b de la CFCS, que regula tanto la votación sobre la base de una iniciativa popular y frente a un eventual contraproyecto. Los ciudadanos con derecho de voto se pronuncian simultáneamente sobre la iniciativa popular o las modificaciones elaboradas a partir de una iniciativa popular y el contraproyecto de la Asamblea Federal. Pueden aprobar ambos proyectos a la vez o bien, la Asamblea Federal deberá pronunciarse explícitamente sobre qué proyecto se discutirá primero y así seguir el orden por ella establecido. 
La CFCS en los dos artículos siguientes del capítulo, vale decir, 140 y 141, ya no distingue por las iniciativas consultadas, sino por el tipo de referéndum (obligatorio y facultativo).

\subsection{Referéndum obligatorio}

El artículo 140 de la CFCS que regula el referéndum obligatorio distingue dos modalidades: una que deberá ser sometido al voto del pueblo y los cantones y otro sólo al pueblo. En el primer caso, el artículo 140.1 de la CFCS prevé tres alternativas de referéndum obligatorio: revisión de la Constitución, adhesión a organizaciones de seguridad colectiva o comunidades supranacionales, y ratificación de las leyes federales declaradas vigentes que estén desprovistas de base constitucional y cuya duración supere un año desde su aprobación.

En el segundo supuesto del artículo 140.2 de la CFCS las iniciativas se consultan sólo al pueblo y se contempla para los siguientes casos: las iniciativas populares para la reforma total de la Constitución, las iniciativas populares generales rechazadas por la Asamblea Federal, y la cuestión de si se debe llevar a cabo una reforma total de la Constitución en caso de desacuerdo entre los dos Consejos.

Así podemos constatar que varios casos de referéndum obligatorios se originan de una iniciativa popular, como los que pudieran surgir de los artículos 138, 139 y 139a de la CFCS. Por otro lado, esta modalidad obligatoria de referéndum opera como una suerte de compensación de los promotores de una iniciativa rechazada por la Asamblea Federal o ante un contraproyecto presentado por ésta.

Finalmente, el artículo 141a de la CFCS establece una norma específica vinculada a la ejecución de los Tratados internacionales: cuando la ratificación de un Tratado internacional esté sometida a referéndum obligatorio, la Asamblea Federal podrá integrar las modificaciones constitucionales ligadas a la ejecución del Tratado, o bien, cuando la resolución mediante la cual quede aprobado un Tratado internacional esté sometida a referéndum, la Asamblea Federal tendrá la facultad de integrar las modificaciones de ley ligadas a la ejecución del Tratado.

\subsection{Referéndum facultativo}

Desde 1848 se estableció la modalidad de referéndum facultativo relativo a las decisiones federales urgentes; la CFCS señala en su artículo 141 esta particular fórmula. En este caso se entrega la iniciativa de la propuesta a la ciudadanía, estableciendo como requisito el que se cuente con el apoyo de 50.000 ciudadanos con derecho a voto, u ocho cantones. Se contempla un plazo de 100 días a contar de la publicación oficial del acto para que dicha propuesta sea sometida a votación popular. 
El mismo artículo limita a determinadas materias la celebración del referéndum facultativo, a saber: las leyes federales; las leyes federales declaradas urgentes cuya validez sobrepase un año; las disposiciones federales, en la medida en que la Constitución o la ley así lo prevean; y los Tratados internacionales que tengan una duración indeterminada y no sean denunciables y prevean la adhesión a un organismo internacional o contengan disposiciones importantes que fijen las reglas de derecho o cuya ejecución exija la adopción de leyes federales.

El referéndum facultativo se establece para iniciativas de menor relevancia que las reformas constitucionales; se exige la mitad de las firmas que para la mencionada reforma y se consulta únicamente al pueblo y no a los cantones.

\section{LA EXPERIENCIA DE LOS REFERENDOS}

Los casos de referendos descritos son igualmente coordinados por el Gobierno Federal, el que determina el calendario y fecha de cada consulta; se han llegado a efectuar referendos en cuatro ocasiones en un año. Generalmente las propuestas federales son consultadas junto con iniciativas locales y cantonales.

El modelo participativo suizo supone, tanto para el referéndum obligatorio como para el facultativo, una minoría que se moviliza contra la decisión mayoritaria del Parlamento. Gerber llamó a este proceso "la campaña directa de preservación". Esto quiere decir que la minoría intenta mantener el status quo oponiéndose a la modificación de la Carta Fundamental u otra norma legal adoptada por la mayoría del Parlamento. ${ }^{38}$

En el caso del referéndum facultativo la minoría opositora ya tuvo que movilizarse para el proceso de admisibilidad tendiente a reunir las firmas necesarias. Por lo tanto, en campañas de referendos facultativos, la mayoría seguramente confrontará a una minoría altamente organizada. Mientras, en los casos de referéndum obligatorio, puede o no conformarse este grupo promotor, dependiendo del supuesto que motive la consulta. Existen modificaciones propuestas por la mayoría del Parlamento que no tienen que ser enfrentadas necesariamente a una oposición estructurada.

En el caso de una iniciativa legislativa popular, la minoría elabora la propuesta, en primera instancia, iniciando una "campaña modificatoria directa”. Aquí se busca alterar el sistema normativo mediante una propuesta ciudadana que generalmente no cuenta con la mayoría parlamentaria. Según Kriesi, la gran cantidad de experiencias sólo da cuenta de un caso donde la mayoría del Consejo Nacional apoyó

38 Gerber, Elisabeth (1999): The Populist Paradox: Interest Group Influence and the Promise of Direct Legislation, (Princeton, Princeton University Press). 
una iniciativa legislativa popular lanzada por la derecha nacionalista, que pedía que el día nacional suizo fuera declarado feriado (septiembre de 1993) ${ }^{39}$

En términos generales podemos concluir la existencia de un bajo nivel de exigencias establecidas para llevar a cabo alguno de los mecanismos previstos por la Carta Fundamental suiza, los que dependerán diferenciadamente de los particulares procedimientos que regulan la participación directa de la ciudadanía. Mientras los casos de referéndum obligatorio son requeridos por la Carta Fundamental, los casos de iniciativa popular contemplan como exigencia la firma de 100 mil ciudadanos dentro de un periodo de 18 meses, y referéndum facultativo requiere, como ya se mencionó, 50 mil firmas dentro de un periodo de 3 meses. En el contexto suizo, 100 mil firmas corresponden a 2,16\% de los ciudadanos, que es una cifra algo menos restrictiva que el requisito exigido por muchos de los sistemas que analizamos en este trabajo.

Por otra parte, en estos procesos participativos, Suiza otorga una particular relevancia a la élite política. Al reconocimiento y preponderancia que tienen los partidos políticos se suma una serie de atribuciones del Gobierno y del Parlamento. Una iniciativa popular, por ejemplo, es sometida antes de su consulta al debate en el Parlamento, pudiendo incidir en la conformación legal de dicha iniciativa a través de sus pronunciamientos sobre su legalidad. Incluso el Parlamento puede adoptar una posición explícita respecto de la iniciativa, recomendando su aceptación o rechazo y pudiendo, incluso, proponer una iniciativa alternativa para ser consultada.

El Parlamento cuenta con la facultad de negociar con los promotores de una iniciativa y, si la rechaza derechamente, tiene la posibilidad de formular una contrapropuesta para someterla a voto popular junto con la iniciativa original, como ya señalamos. Los promotores de la iniciativa, a su vez, pueden negociar con el Parlamento, el texto y retirarlo si la propuesta parlamentaria cumple con sus expectativas. Según nos señala Kriesi, sólo el 7\% de los actos legislativos sometidos a referéndum facultativo ha sido objeto de alguna observación por parte de los órganos del Estado. ${ }^{40}$

A su vez, el Gobierno cuenta con varios mecanismos para orientar un proceso de consulta. Tiene el derecho a presentar su punto de vista en un documento de difusión masiva que es enviado a cada ciudadano; dicho informativo si bien da cuenta de la posición de los oponentes, destaca el punto de vista del gobierno primero y con mayor detalle. Además, no hay límites en cuanto a contribuciones a las campañas por parte de actores que no pertenezcan al Gobierno, y no es requerido hacer públicas las contribuciones realizadas a las diferentes campañas. ${ }^{41}$

\footnotetext{
39 KRIESI (2008), p. 25.

${ }^{40}$ KrIesi (2008), pp. 19 y s.

${ }^{41}$ KrIesi (2008), p. 23.
} 
Con todo, según da cuenta Neidhart, ya en la década del setenta el referéndum había causado un profundo impacto en el proceso de toma de decisiones de la élite política, al forzar que todos los participantes, en cada etapa del proceso de toma de decisiones, anticiparan un posible veto popular. Tanto el referéndum facultativo como el obligatorio estimulan la integración al proceso de toma de decisiones de importantes grupos de interés, capaces de promover consultas populares en sus diversas modalidades. Según este autor, la existencia de mecanismos participativos en el sistema institucional suizo ha transformado la "democracia plebiscitaria" en una "democracia de negociación" y ha contribuido de manera decisiva a la orientación de consensos como característica del sistema institucional suizo. ${ }^{42}$

El particular sistema político suizo permite que aun miembros de una gran alianza de partidos puedan oponerse al Gobierno en temas específicos a través de la utilización de mecanismos de democracia directa. En otras palabras, no son solamente los pequeños partidos de oposición (de derecha o izquierda) quienes pueden rechazar un proyecto de ley que cuente con el apoyo mayoritario del Parlamento, o proponer iniciativas para nueva legislación; también lo hacen partidos que son parte de la coalición gobernante. Los procedimientos de democracia directa, en otras palabras, permiten oposición basada en proyectos puntuales sin cuestionar el programa de gobierno en su conjunto.

Es importante señalar que los promotores de una consulta ciudadana se integran no sólo con militantes de partidos políticos; también se alinean con varias otras organizaciones políticas que tienen interés en el pronunciamiento ciudadano. La sociedad suiza es altamente organizada, lo que significa que, además de partidos, hay un gran número de grupos de interés, movimientos y organizaciones sociales que participan activamente de la política, sumándose a coaliciones partidarias. Todas estas agrupaciones tienen una determinada tendencia política y generalmente se puede identificar su presencia en determinados grupos promotores de mecanismos de democracia directa. ${ }^{43}$

\footnotetext{
${ }^{42}$ NeIdHART, Leonhard (1970): Plebiszit und pluralitäre Demokratie. Eine Analyse der Funktion des schweizerischen Gesetzesreferendums, (Berne, A. Francke Verlag).

43 En la derecha las más importantes son las asociaciones de intereses empresariales. Están divididas en cuatro asociaciones principales: la asociación industrial encabezada por "economiesuresse", la asociación de empleados, la asociación de pequeños empresarios y comerciantes, y la asociación de agricultores. En campañas de democracia directa las asociaciones empresariales normalmente se juntan con fuerzas de la derecha moderada. Además de estas asociaciones hay un número de asociaciones de intereses especiales que se adhieren a alguna de las subdivisiones en la derecha según temas específicos. En la izquierda, hay dos tipos de asociaciones que entran en juego, principalmente el movimiento ecologista y el movimiento pacifista. Hay tres sistemas sindicales importantes: los sindicatos socialistas, los sindicatos cristianos y las asociaciones de empleados. Estas organizaciones normalmente se unen a las coaliciones de izquierda o a algún partido de la izquierda radical. KRIESI (2008), pp. 31 y sig.
} 
Ahora, dada la posición minoritaria de la izquierda en las últimas décadas se podría esperar que las consultas sean lideradas principalmente por este sector. No obstante, la función de veto del referéndum lo convierte en instrumento ideal para los sectores parlamentarios que no han logrado incorporar su perspectiva en alguna iniciativa. Así podemos identificar propuestas vinculadas a prácticamente todo el espectro político. Bloquear una propuesta legislativa significa mantener el status quo que puede ser aún menos atractivo para la minoría política. Es decir, una minoría sólo tiene incentivo para cuestionar una propuesta legislativa o constitucional si el cambio propuesto va contra sus intereses o si, desde su punto de vista, las ventajas presentadas son demasiado limitadas.

No obstante, en un reciente estudio efectuado por Kriesi, que analiza las experiencias participativas realizadas en el período 1945-1978, se indica que el 80\% de las iniciativas de nivel federal tuvo su origen en movimientos de izquierda, mientras que en un $73.7 \%$ el referéndum facultativos es identificado mayoritariamente con sectores relacionados con la derecha suiza. Según este autor, desde los noventa a la fecha dicha tendencia se mantiene; así la iniciativa legislativa popular tiende a identificarse más con los grupos progresistas y el referéndum facultativo con los grupos conservadores. ${ }^{44}$

Pese al amplio margen de alternativas que hemos descrito, el referéndum obligatorio es la fórmula más utilizada en la democracia suiza. Cuantitativamente representa más de un $30 \%$ de las experiencias implementadas a partir de las fórmulas reconocidas en la CFCS. En concreto, se han implementado más de 500 consultas obligatorias, frente un centenar de iniciativas populares de ley y referendos facultativos. ${ }^{45}$

En general, las temáticas consultadas son de diversa naturaleza, concentrándose fundamentalmente en materias económicas, medioambientales, de organización política del Estado, de defensa, de agricultura, de inmigración, entre otras.

Durante las décadas de los ochenta y noventa fueron consultadas las reformas de los principales órganos constitucionales de la actual carta de 1999: la Corte Federal, el Parlamento, el Consejo Federal y la Administración Federal. Esto junto con modificaciones menores de la división territorial interna como la creación del cantón de Jura. No obstante, podemos identificar otras materias relevantes. Por ejemplo, se han realizado recientemente tres intentos para modificar la estructura de la política fiscal federal, dos de ellos específicamente diseñados para lidiar con el déficit en el presupuesto federal. También se pre-

${ }^{44}$ KrIEsI (2008), p. 33.

45 Ulieri (2003), pp. 224 a 225. 
sentaron propuestas para la modificación del impuesto al transporte y varias referidas a iniciativas para recortar subsidios menores. La consulta más reciente en el ámbito económico fue efectuada en marzo de 2004 referida a una nueva organización de las finanzas federales.

Otra iniciativa destacable que tiene que ver con el plano productivo se realizó en el año 2005. Se consultó y aprobó una iniciativa que, con el nombre de "cultivando sin modificaciones genéticas", buscó avanzar en reformas ecológicas en la agricultura suiza.

Los temas culturales, incluyendo las políticas educacionales, son principalmente delegados a los gobiernos locales y cantonales, pero existen todavía algunas reformas que se tratan a nivel nacional. Entre ellas están: la aprobación de nuevos artículos a la Constitución Federal que regulan radio y televisión, la política cultural federal y la relación entre idioma y comunidades. La última de estas modificaciones data del año $2006 .{ }^{46}$

Consultas referidas a la política exterior y de defensa, y las directrices migratorias han generado una intensa controversia. Particularmente el referéndum sobre la participación suiza en la Unión Europea, las Naciones Unidas y el Fondo Monetario Internacional han motivado cinco votaciones populares consecutivas. Las iniciativas vinculadas a la defensa nacional han sido dominadas por la movilización de organizaciones pacifistas que se concentran en exigir la supresión del ejército suizo. También se han realizado consultas específicas referidas a la compra de aviones de combate y de predios para entrenamiento militar. A su vez, la política migratoria ha llegado a ser un tema controvertido entre los partidos políticos y organizaciones sociales vinculados a la izquierda y la derecha suiza. Se ha consultado si extranjeros pueden adquirir propiedades en Suiza, las medidas destinadas a establecer el control general de los extranjeros en el país, entre otras iniciativas. El tema del asilo político también ha sido objeto de varios debates de democracia directa; el último fue consultado el 16 de diciembre de $2005 .{ }^{47}$

Otro conjunto de referendos e iniciativas populares puede ser vinculado a la continuidad del sistema de seguridad social suiza. Así podemos identificar consultas referidas al establecimiento de seguros para ancianos, médicos, de maternidad, de desempleo, entre otros. Aquí se concentran muchas de las últimas iniciativas populares presentadas, como la que estableció un seguro para enfermedades, de marzo de 2007; la que creó el Banco Nacional para adultos mayores, de septiem-

46 López, Jaume y Requejo, Ferran (2009): Análisis de experiencias de democracia directa en el ámbito internacional (1995-2007), (Bilbao, IVAP), p. 123.

${ }^{47}$ KRIESI (2008), p. 40. 
bre del 2006; que aseguró servicios postales para todos, de septiembre del 2004, entre otras. ${ }^{48}$

Según Kriesi, la materia que concitan el mayor número de experiencias participativas es la medioambiental. Este autor reúne bajo dicho título, diversas temáticas como política energética, transporte, planeación territorial y protección al consumidor. Cabe destacar entre todas ellas, por su impacto público en la década de los ochenta, la política energética, que ha sido dominada por la activación del movimiento antinuclear. Las consultas vinculadas al transporte son recurrentes en casi todas las décadas, dando pie al establecimiento de impuestos, a la construcción de caminos nacionales y vías rápidas para trenes, túneles y a definiciones sobre transporte público, entre otras materias sometidas a referéndum y a iniciativas populares. En cuanto a temas ecológicos encontramos iniciativas llamando a la protección de lugares específicos (Rothenturm y las regiones de los Alpes), así como propuestas para proteger el agua. Temas de investigación son incluidos en esta categoría, ya que se relacionan en parte con el movimiento ecologista (uso de animales en experimentos de laboratorio y de ingeniería genética). ${ }^{49}$

Pocas consultas han alcanzado notoriedad pública. La falta de visibilidad sin duda incide en la participación, que regularmente no supera el 60\% del padrón electoral. Entre los años 1972 y 1975 se llegó al promedio más bajo de participación, con sólo un $35,2 \%$, mientras que las consultas más participativas se registraron en $1882(76,3 \%)$ y 1889 (70,9\%). Esta falta de interés ciudadano tiene como fundamento: los proceso de negociación (que va desmovilizando a sectores satisfechos con nuevas ofertas), al carácter colegiado de las instituciones (comprometiendo en la dirección de órganos de decisión política a un amplio espectro político) y al grado de complementariedad horizontal y vertical de la gestión pública. Todos estos factores institucionales explican la sistemática pérdida de protagonismo de los mecanismos de democracia directa a nivel federal. ${ }^{50}$

No obstante, algunas consultas han concitado una amplia participación ciudadana. Por ejemplo, en 1989, la iniciativa legislativa popular que establecía la abolición del ejército convocó a más del 68,6\% del electorado. La definición sobre la participación suiza en la CEE también atrajo al electorado en 1992. Con una mayoría de 50,3\%, finalmente se rechazó el ingreso a esta plataforma, transformándose aquél en el referéndum con mayor participación en la historia de Suiza (participó el 78,3\% del padrón electoral). Por otra parte, el referéndum que mayor

48 López y Requejo (2009), pp. 123 a 125.

49 Kriesi (2008), p. 43.

${ }^{50}$ Ulieri (2003), p. 226. 
debate concitó en la opinión pública suiza fue el dedicado a zanjar el ingreso a la ONU en el año 2002 que, con más de 54,6\% de aprobación, revertió la tendencia de este Estado por marginarse de organizaciones internacionales. ${ }^{51}$

Sin duda una de las experiencias que atrajo la atención mundial, como hemos dicho, se produjo recientemente, el 29 noviembre del 2009, cuando a través de una iniciativa popular dirigida a reformar parcialmente la Constitución se aprobó, mediante referéndum, la propuesta de prohibir en la Carta Fundamental la construcción de minaretes en las mezquitas que se edificaran en el futuro en Suiza. En concreto se agrega un nuevo párrafo al artículo 72 de la CFCS referido a la libertad de culto. Esta iniciativa popular fue aprobada por una mayoría de votantes y aprobada por 22 de los cantones (sólo los cantones de Ginebra, Vaud, Neuchatel, Basilea-Ciudad la rechazaron). El principal apoyo de esta iniciativa surgió de los partidos de derecha populista (Partido Popular de Suiza y la Unión Democrática Federal), mientras que todos los otros sectores se opusieron a ella, y hasta la Asamblea Federal recomendó oficialmente su rechazo a la ciudadanía. Esta consulta concitó la atención de la prensa europea y mundial debido a la virulencia de la campaña de los grupos promotores, que distribuyó carteles en todo el país con "minaretes" amenazantes cual misiles. Pese a la oposición del Gobierno de la mayoría parlamentaria, y a que días antes de la votación Amnistía Internacional advirtió que la prohibición impediría a Suiza el respetar sus compromisos en materia de libertad de culto, un 57,5\% de los votantes respaldó la iniciativa (con una tasa de participación que se situó alrededor del $55 \%$ ). Sin duda este referéndum va a permitir observar cómo asume la Asamblea Federal las atribuciones establecidas en el artículo 139.2 y que ya hemos explicado anteriormente.

Con todo, la nutrida práctica participativa que hemos descrito en Suiza no llega a alterar sustancialmente la gestión de los órganos representativos de gobierno. Los referendos e iniciativas populares de ley que se suceden año a año tienden a impactar comúnmente en otras dimensiones como la generación de nuevas oportunidades para participación y para incrementar los niveles de cohesión ciudadana. En consecuencia, más que opacar o competir con la labor que desempeñan los representantes, estos mecanismos son un factor de complemento y potenciación de su gestión pública. Así hemos hecho referencia al vínculo directo que varios estudios distinguen entre la participación directa de la ciudadanía y la calidad del debate público, la capacidad de recepción de las demandas ciudadanas, entre otras consecuencias detectadas.

${ }^{51}$ ULIERI (2003), p. 216. 
Incluso las investigaciones aludidas destacan el rol gravitante de los grupos de interés y partidos políticos en la generación de los propios procesos consultivos. La experiencia suiza devela la particular relevancia que tienen los partidos políticos en la implementación y efectos de las fórmulas participativas. Las instituciones de democracia directa llegan a brindar verdaderos incentivos para que los partidos políticos efectúen concesiones y encuentren soluciones consensuadas en numerosas iniciativas populares. Dependiendo del tipo de instrumento y la lógica institucional, las posibilidades de la élite dirigente de controlar los procesos participativos pueden variar. Un mecanismo como la iniciativa popular -que típicamente se usa para modificar el status quo- da a los partidos políticos más influencia durante la campaña que el referéndum (utilizado para mantener el estado de las cosas). Esto se hace evidente también en el caso del referéndum facultativo, donde la necesidad de presentación de una iniciativa debe cumplir el proceso previo de admisibilidad y, para ello, supone el trabajo articulado de organizaciones en todo el país.

Los trabajos citados de Kriesi, Gerber y Tauxe demuestran que en la mayoría de los casos el nivel de organización requerido para acompañar en cada una de sus etapas una iniciativa popular o un referéndum facultativo sólo es cubierto por los partidos políticos y grandes organizaciones de la sociedad civil con presencia en todo el país. Con todo, es justamente este supuesto organizacional uno de los motivos dado por estos autores para que estas fórmulas no sean utilizadas por posiciones populistas y desinformadas. Mientras los movimientos ciudadanos conforme coaliciones claramente estructuradas y ofrezcan sólidos argumentos para la definición de las consultas, este modelo participativo establecerá grados crecientes de complementariedad con los órganos representativo.

Esto es lo que Kriesi llama "la pre-estructuración de la decisión”. Bajo este concepto se considera desde la fórmula concretamente utilizada para consultar, la manera en que ésta se comunique a la ciudadanía, las estrategias que en definitiva adopte el comité promotor, las organizaciones sociales y los partidos políticos durante el proceso de consulta, entre otros factores que determinan la participación en estos procesos de consulta. El uso de mecanismos de democracia directa impone a las organizaciones sociales y a los partidos políticos la exigencia de entregar mensajes coherentes no sólo en su discurso, sino en su accionar. Así, al momento de verse enfrentadas a los procesos de consulta popular la ciudadanía debe saber identificar el conflicto que se pretende resolver mediante su participación. Lo que la experiencia suiza indica, a juicio de este autor, es que la calidad de las decisiones participativas puede verse incrementada en el número de ciudadanos involucrados y el nivel del debate, por un diseño institucional adecuado y por apropiadas estrategias de difusión. En este 
análisis las decisiones ciudadanas se encuentran directamente vinculadas con los argumentos presentados y por sus esfuerzos de llevar estos argumentos a la atención de los votantes. ${ }^{52}$

En consecuencia, el aporte de los mecanismos de democracia directa no se logra con su sola explicitación a nivel constitucional; se requiere todo un tramado institucional que los relacione con organizaciones de la sociedad civil, partidos políticos y órganos constitucionales. Suiza particularmente muestra una larga evolución en la construcción de este proceso de articulación participativa.

\section{REFLEXIÓN FINAL}

Hemos evidenciado en este somero análisis de la regulación y práctica de los mecanismos de democracia directa, contemplados en la Carta Fundamental suiza, su coherencia con el modelo consensual de gobierno y su uso acotado en el proceso legislativo y de reforma constitucional. Los autores analizados destacan la funcionalidad de este modelo participativo en el proceso de establecer consensos entre los diversos sectores políticos y de fortalecer el vínculo de las instancias de representación con la ciudadanía. Esto nos lleva a concluir que el actual estatus de los mecanismos de democracia directa en el sistema institucional suizo, por lo menos en su nivel nacional, complementa al sistema representativo. Más que instrumentos de definición cotidiana, dichas instituciones operan en subsidio y en el evento que una propuesta no alcance el grado de consenso requerido en la mayoría de los casos.

Tauxe, analizando los casos presentados de iniciativas populares en los últimos años, destaca el papel que tienen los partidos en su elaboración y posterior debate parlamentario. A juicio de este autor, la relación entre partidos políticos y mecanismos de democracia directa se puede evidenciar en la concreción dichas iniciativas. Desde 1891, fecha de la introducción del derecho de iniciativa popular en cuanto a revisión constitucional parcial, sobre un total de cerca de 160 iniciativas, sólo quince lograron terminar su trámite legislativo y ser finalmente promulgadas. El rol de los partidos políticos fue clave en cada una de ellas. ${ }^{53}$

Esta idea es confirmada por otros estudios que analizan la práctica referendaria, como los realizados por Druckman y Nelson ${ }^{54}$, y el más reciente efectuado por Kriesi, coincidiendo en que la ciudadanía suiza determina su participación

\footnotetext{
52 KRIESI (2008), p. 75.

53 Tauxe (2007), p. 450.

54 Druckman, James, y otro (2003): "Framing and deliberation: How citizens' conversations limit elite influence", American Journal of Political Science, (Núm. 47), pp. 729 a 745.
} 
principalmente a partir de las opiniones que escucha de los partidos políticos y de las organizaciones sociales. ${ }^{55}$

En el ámbito nacional las iniciativas de reforma legal o constitucional son una clara expresión de este proceso de construcción de consensos "desde abajo". Esta debe incorporar la sensibilidad de los cantones, de las distintas perspectivas ciudadanas, políticas y religiosas, entre otras, ya que siempre está la alternativa que un grupo disconforme utilice algunos de los mecanismos participativos con el objetivo de dilatar su discusión o simplemente abortarla a través de una definición popular. Así la evolución institucional suiza da cuenta de distintas fórmulas que buscan disminuir al mínimo el surgimiento estos grupos adversos, buscando integrar las diversas sensibilidades presentes en la sociedad. En este sentido nos encontramos con todo un tramado participativo orientado a incorporar dentro del modelo institucional la expresión de grupos generados de manera espontánea y con poca capacidad de estructurarse de manera permanente. Las alternativas de participación no se restringen a los mecanismos como el referéndum o la iniciativa legislativa popular. Más bien, estos mecanismos permiten que propuestas que no logran cumplir con los estándares exigidos por la Constitución y la ley puedan orientarse a otras alternativas institucionales como las aludidas Comisiones Asesoras o bien, se integren a alguna iniciativa parlamentaria.

Por otra parte, al no disponer Suiza de un control jurisdiccional completo, debido a que las leyes federales no están sujetas a la jurisdicción del Tribunal Federal, es la ciudadanía la que fiscaliza el proceso legislativo a través de mecanismos de democracia directa. Ésta es sin duda otra particularidad del modelo suizo generalmente no enfatizada. En la mayoría de los sistemas institucionales que analizaremos, sean parlamentarios o presidenciales, el referéndum opera como fórmula para resolver conflictos en el proceso formativo de las leyes o bien ante conflicto entre órganos constitucionales. Sólo en Suiza podemos identificar un rol preponderante de la ciudadanía en el resguardo de la constitucionalidad, impactando en la forma de Estado, al alejarse de la democracia constitucional. En definitiva, la multiplicidad de objetivos descritos y que se resguardan a través de los mecanismos de democracia directa es sin duda un sello del modelo institucional suizo.

Con todo, el sistema institucional suizo ha evolucionado hacia establecer límites en las decisiones de la mayoría popular. Así hemos aludido a la reforma

\footnotetext{
${ }^{55}$ Este último estudio propone un análisis sistemático de la manera en que se llevan a cabo decisiones de democracia directa en Suiza, con énfasis particular en las decisiones a nivel nacional, abarcando 148 propuestas sometidas a voto popular entre 1981 y 1999. Se trata de los resultados de 49 encuestas representativas a ciudadanos suizos llevadas a cabo en las semanas posteriores a las fechas electorales. KRIESI (2008), p. 9.
} 
constitucional del año 2003, que permite a la Asamblea Federal declarar total o parcialmente nula una iniciativa de reforma constitucional cuando no respete disposiciones imperativas de derecho internacional. En este sentido la experiencia suiza debería ser tomada en cuenta por quienes ponen en duda el carácter constitucional y el existencia de mecanismos de reguardo a los derechos fundamentales, amparándose en la voluntad las mayorías ciudadanas. ${ }^{56}$

\section{BibLIOGRAFíA}

A.A.V.V. Derechos y libertades en los Estados Compuestos, (Barcelona, Editorial Atelier);

Argullol Murgadas, Enric (2004): Federalismo y autonomía, Barcelona, Editorial Ariel);

Auer, Andreas, Malinverni, Giorgio, HotTelier, Michel (2000): Droit constitutionnel suisse, (Bern, Staempfli);

BLONDEL, Jean (1998): “Il modello svizzero, un futuro per I' Europa?”, Revista italiana di Scienza Política,( Núm. 2), pp. 203 a 227;

DE VERGOTTINI, Giuseppe (1985): Derecho Constitucional Comparado, (Madrid, Espasa-Calpe);

DruCKMAN, James y otro (2003): "Framing and deliberation: How citizens' conversations limit elite influence", American Journal of Political Science, (Núm. 47), pp. 729 a 745 ;

FELD, Lars y KIRCHGÄSSNER, Gebhard (2001):

"The political economy of direct legislation: Direct democracy and local decisionmaking", Economic Policy, (Núm. 16), pp. 329 a 367;

FioraVANTI, Maurizio (2007): Constitución, de la antigüedad a nuestros días, (Madrid, Editorial Trotta);

Frey, Bruno y Stutzer, Alois (2002): Happiness and Economics, (Princeton and Oxford, Princeton University Press)

"Does direct democracy reduce public debt evidence from Swiss municipalities", Public Choice, (Núm. 109), pp. 347 a 370;

Gerber, Elisabeth (1999): The Populist Paradox: Interest Group Influence and the Promise of Direct Legislation, (Princeton, Princeton University Press);

Jaria Manzano, Jordi (2001): "El federalismo suizo, una respuesta a una sociedad plural”, Revista Vasca de Administración Pública, (Núm. 61), pp. 89 a 136;

\footnotetext{
56 Waldron, Jeremy (1999): Law and Disagreement, (Oxford, Oxford University Press), pp. 265 y ss.
} 
KRIESI, Hanspeter (2008): Direct democratic choice, the Swiss Experience, (Lanham Lexington Books) y (1995): Le sytème politique suisse, (París, Economica);

LijpharT, Arend (1999): Patterns of democracy, (New Haven, Yale University Press);

Loewenestein, Karl (1979): Teoría de la Constitución, (Barcelona, Ariel);

LópeZ, Jaume y Requejo, Ferran (2009): Análisis de experiencias de democracia directa en el ámbito internacional (1995-2007), (Bilbao, IVAP);

Lupia Arthur y MatsusaKa John G. (2004): "Direct Democracy: New Approaches to Old Questions”, Annual Review of Political Science, (Núm.7), pp. 463 a 482;

NeIdHART, Leonhard (1970): Plebiszit und pluralitäre Demokratie. Eine Analyse der Funktion des schweizerischen Gesetzesreferendums, (Berne, A. Francke Verlag);

Papadopoulos, Yannis (1997): Les processus de decisión fédéraux en Suisse, (Paris, L'Harmattan);

Sánchez FerRIZ, Remedio (2001): Suiza sistema político y constitucional, (Madrid, CEC);

Tarr, Allan (1998): Understanding State Constitutions, (Princeton, Princeton University Press);

TAuXE, Lionel (2007): "La concrétisation législative des initiatives populaires fédérales acceptées en votation: un processus aux outputs très incertains", Swiss Political Review, (Núm. 13), pp. 433 a 458;

ULIERI, Pier Vincenzo (2003): Referendum e Democrazia, una prospecttiva comparata, (Bologna, Il Mulino);

Vatter, Adrian (2002): Kantonale Demokratien im Vergleich. (Opladen, Leske + Budrich), $\mathrm{y}$

Waldron, Jeremy (1999): Law and Disagreement, (Oxford, Oxford University Press). 